\title{
ANALISIS KINERJA BUNDARAN DUHUNG DI KOTA KUALA KURUN KABUPATEN GUNUNG MAS
}

\author{
PERFORMANCE ANALYSIS OF DUHUNG'S ROUNDABOUT IN KUALA KURUN CITY \\ GUNUNG MAS REGENCY
}

\author{
Andika $^{* 1}$, Murniati ${ }^{2}$, Laufried ${ }^{3}$ \\ ${ }^{1}$ Mahasiswa, Program Studi Teknik Sipil, Universitas Palangka Raya \\ 2,3 Dosen, Program Studi Teknik Sipil, Universitas Palangka Raya \\ *Korespondensi: andika114069@gmail.com
}

\begin{abstract}
ABSTRAK
Perubahan volume lalu lintas yang melewati bundaran duhung memberikan dampak pada kondisi lalu lintas. Penelitian ini bertujuan untuk mengetahui volume lalu lintas, kinerja bundaran dan bentuk geometri jalan. Metode yang digunakan yaitu MKJI 1997. Hasil analisis menunjukkan bahwa jalinan Bundaran Duhung tahun 2020 memiliki nilai arus bagian jalinan terbesar yaitu $815 \mathrm{smp} / \mathrm{jam}$ pada jalinan AB (Jalan Ahmad Yani-Jalan Tjilik Riwut), kapasitas terbesar pada jalinan AB (Jalan Ahmad Yani-Jalan Tjilik Riwut), yaitu 6.803 smp/jam, dengan nilai derajat kejenuhan tertinggi dari jalinan CD (Jalan Kopri-Jalan Tjilik Riwut) yaitu 0,274, tundaan lalu lintas bundaran rata-rata (DTR) yaitu 2,07 det/smp, tundaan bundaran rata-rata (DR) yaitu 6,07 det/smp dan termasuk karakteristik tingkat pelayanan pada kondisi sekarang adalah kelas A. Geometrik Bundaran Duhung memiliki nilai kelandaian terbesar yaitu $-5,800 \%$, pada lengan D (Jalan Tjilik Riwut), pada lengan A (Jalan Ahmad Yani) yaitu 2,824\%, pada lengan B (Jalan Tjilik Riwut) yaitu 1,424\%, pada lengan C (Kopri) yaitu $3,425 \%$, dari hasil penelitian geometrik bundaran pada lengan D (Jalan Tjilik Riwut) tidak memenuhi syarat batas maksimum yaitu $4 \%$, sehingga mengurangi kenyamanan pengguna jalan.
\end{abstract}

Kata kunci: :Bundaran, Derajat Kejenuhan, Jalinan, Tingkat Pelayanan, Tundaan

\section{ABSTRACT}

Changes in the volume of traffic passing through Duhung roundabout have an impact on traffic conditions. This study aims to find out traffic volume, roundabout performance and road geometric shapes. The method used is MKJI 1997. Analysis shows that the weaving Bundaran Duhung in 2020 has the largest weaving flow value of 815 pcu/hour on the AB interlace (Ahmad Yani Street - Tjilik Riwut Street), the largest capacity on weaving AB (Ahmad Yani Street - Tjilik Riwut Street), which is 6803 pcu/hour, with the highest saturation degree of weaving CD (Kopri Street - Tjilik Riwut Street) which is 0.274 , the average roundabout traffic delay $\left(D T_{R}\right)$ is $2.07 \mathrm{sec} / \mathrm{pcu}$, the average roundabout delay $(D R)$ is $6.07 \mathrm{sec} / \mathrm{pcu}$ and includes the characteristics of service level in the current condition is class A. Geometric Duhung Roundabout has the largest value of -5,800\%, on arm D (Tjilik Riwut Street), on arm A (Ahmad Yani Street) which is $2.824 \%$, on arm B (Tjilik Riwut Street) which is $1.424 \%$, on arm C (Kopri Street) which is $-3.425 \%$, from geometric research results of roundabout on arm $D$ (Tjilik Riwut Street) does not meet the maximum limit of 4\%, thus reducing the comfort of road users.

Keywords: Roundabout, Degree of Saturation, Delay, Service Level, Weaving 


\section{PENDAHULUAN}

Transportasi merupakan salah satu kebutuhan bagi kehidupan masyarakat modern, pemanfaatan teknologi yang berkembang dengan pesat serta laju pertumbuhan penduduk yang semakin meningkat dari tahun ke tahun mengakibatkan kebutuhan akan transportasi semakin tinggi.

Untuk mendukung pergerakan manusia dan barang yang aman, cepat, dan nyaman, pada suatu jalan perlu adanya pengaturan lalu lintas yang baik. Pada persimpangan biasanya pengaturan arus lalu lintas menggunakan rambu-rambu lalu lintas, lampu lalu lintas dan taman bundaran. Bundaran adalah salah satu bentuk pertemuan jalan yang berfungsi sebagai pengontrol pembagi dan pengaruh sistem lalu lintas berputar satu arah.

Bundaran Duhung merupakan salah satu bundaran yang ada di kota Kuala Kurun, Kabupaten Gunung Mas. Bundaran ini melayani arus penting yaitu arus lalu lintas yang dilewati oleh kendaraan yang keluar dan masuk kota maupun pergerakan kendaraan dalam kota karena kondisi tata guna lahan daerah sekitar yang akan terjadinya bangkitan dan tarikan perjalanan yang cukup besar karena adanya perkantoran, perumahan, sekolah dan rumah sakit dengan jenis kendaraan yang bervariasi seperti sepeda motor, mobil, dan kendaraan berat, sehingga diperlukan proyeksi arus lalu lintas kedepannya untuk mengetahui apakah bundaran tersebut dapat memenuhi kebutuhan dari arus kendaraan. Bundaran Duhung adalah satu dari tiga bundaran yang ada di kota Kuala Kurun Kabupaten Gunung Mas.

\section{TINJAUAN PUSTAKA}

\section{Persimpangan (Intersection)}

Persimpangan adalah suatu daerah umum dimana dua arus jalan atau lebih bergabung atau berpotongan, termasuk fasilitas-fasilitas yang ada di pinggir jalan untuk pergerakan lalu lintas pada daerah tersebut. (Morlok,1991). Secara garis besar, persimpangan terbagi dalam dua bagian, yaitu persimpangan sebidang dan persimpangan tidak sebidang.

\section{Bundaran}

Bundaran (roundabout) merupakan sebuah pulau lingkaran yang ditempatkan dibagian tengah pada suatu persimpangan. Pengemudi yang melewati simpang tersebut harus mengitari pulau bundaran tersebut searah dengan jarum jam.

Bundaran merupakan alternatif lain pengganti lampu lalu lintas untuk pengaturan pada persimpangan. Bundaran lebih dipilih untuk menghindari problem pada persimpangan akibat pergerakan yang berkonflik satu sama lain, terutama kendaraan yang membelok ke kanan, karena dinilai dapat menghasilkan antrian ruang lebih kecil pada periode jam sibuk dibandingkan dengan lampu lalu lintas (Morlok, 1991).

Bundaran berfungsi sebagai pengontrol pembagi dan pengaruh sistem lalu lintas berputar satu arah. Tujuan utama bundaran adalah melayani gerakan yang menerus, namun hal ini tergantung dari kapasitas dan luas daerah yang dibutuhkan. (Hobbs, 1995).

Tipe bundaran berdasarkan MKJI 1997 terbagai atas berbagai macam, seperti yang terlihat pada Tabel 1.

Tabel 1. Tipe Bundaran dan Karakteristknya

\begin{tabular}{cccccc}
$\begin{array}{c}\text { Tipe } \\
\text { bundaran }\end{array}$ & $\begin{array}{c}\mathrm{W}_{1} \\
(\mathrm{~m})\end{array}$ & $\begin{array}{c}\mathrm{W}_{1} \\
(\mathrm{~m})\end{array}$ & $\begin{array}{c}\mathrm{W}_{\mathrm{E}} \\
(\mathrm{m})\end{array}$ & $\begin{array}{c}\mathrm{W}_{\mathrm{w}} \\
(\mathrm{m})\end{array}$ & $\begin{array}{c}\mathrm{L}_{\mathrm{w}} \\
(\mathrm{m})\end{array}$ \\
\hline $\mathrm{R} 10-11$ & 10 & 1 & 3,5 & 23 & 7 \\
$\mathrm{R} 10-12$ & 10 & 2 & 7,0 & 27 & 9 \\
$\mathrm{R} 14-22$ & 14 & 2 & 7,0 & 31 & 9 \\
$\mathrm{R} 20-22$ & 20 & 2 & 7,0 & 43 & 9 \\
\hline
\end{tabular}

Sumber : MKJI, 1997

\section{Kapasitas Jalinan Bundaran}

Kapasitas bundaran dapat didefinisikan sebagai banyaknya kendaraan yang dapat ditampung oleh jalan tersebut dalam waktu tertentu. Kapasitas total bagian jalinan bundaran adalah hasil perkalian antara kapasitas dasar (Co) dan faktor koreksi $(\mathrm{F})$, dengan memperhitungkan pengaruh kondisi lapangan sesungguhnya ter-hadap kapasitas. (MKJI,1997).

Untuk menghitung kapasitas pada bundaran, dapat menggunakan rumus sebagai berikut (MKJI,1997):

$$
\mathrm{C}=135 \times \mathrm{W}_{\mathrm{w}}^{1,3} \times\left(1+\mathrm{W}_{\mathrm{E}} / \mathrm{W}_{\mathrm{W}}\right)^{1,5} \times\left(1-\mathrm{P}_{\mathrm{W}} / 3\right)^{0,5} \times(1
$$$$
\left.+\mathrm{W}_{\mathrm{W}} / \mathrm{L}_{\mathrm{W}}\right)^{-1,8} \mathrm{x} \mathrm{F}_{\mathrm{CS}} \times \mathrm{F}_{\mathrm{RSU}} \ldots \ldots \ldots \ldots \ldots \ldots \ldots \ldots . .(1)
$$

Faktor penyesuain FCS untuk ukuran kota berdasarkan padajumlah penduduk kota sebagaimana pada Tabel 2. 
Tabel 2. Faktor Penyesuaian Ukuran Kota

\begin{tabular}{ccc}
$\begin{array}{c}\text { Ukuran kota } \\
(\mathrm{CS})\end{array}$ & $\begin{array}{c}\text { Penduduk } \\
\text { (juta) }\end{array}$ & $\begin{array}{c}\text { Faktor } \\
\text { penyesuaian } \\
\text { ukuran kota }\left(\mathrm{F}_{\mathrm{cs}}\right)\end{array}$ \\
\hline Sangat kecil & $<0,1$ & 0,82 \\
Kecil & $0,1-0,5$ & 0,88 \\
Sedang & $0,5-1,0$ & 0,94 \\
Besar & $1,0-3,0$ & 1 \\
Sangat besar & $>3,0$ & 1,05 \\
\hline
\end{tabular}

Sumber : MKJI,1997

\section{Volume Lalu Lintas}

Volume lalu lintas adalah satuan pengukuran jumlah arus lalu lintas yang ditunjukkan oleh jumlah kendaraan atau jumlah penggunaan jalan yang melewati suatu titik pengamatan dalam satuan waktu, baik dalam hari, jam, dan menit (Hobbs, 1995).

Data lalu lintas dibagi dalam beberapa tipe kendaraan yaitu kendaraan ringan (LV), ken-daraan berat (HV), sepeda motor (MC) dan kendaraan tak bermotor (UM). Arus lalu lintas tiap pendekat dibagi dalam tipe pergerakan, antara lain: gerakan belok kanan (RT), belok kiri (LT), dan lurus (ST). Arus lalu lintas ini kemudian dikonversi dari kendaraan per jam menjadi satuan mobil penumpang (smp) dengan menggunakan ekuivalen mobil penumpang (emp) dengan nilai LV:1,0; $\mathrm{HV}: 1,3$ dan MC:0,5.

\section{Derajat Kejenuhan}

Kinerja lalu lintas merupakan ukuran pelayanan lalu lintas yang diperoleh oleh pengguna jalan. Salah satu ukuran kinerja lalu lintas ada-lah derajat kejenuhan. Derajat kejenuhan bagi-an jalinan dapat dihitung sebagai berikut (MKJI,1997):

$\mathrm{DS}=\mathrm{Q} / \mathrm{C}$

dimana $\mathrm{Q}$ adalah arus total dan $\mathrm{C}$ adalah kapasitas.

\section{Tundaan Bagian Jalinan Bundaran}

\section{Tundaan Lalu Lintas Bagian Jalinan (DT)}

Tundaan Lalu Lintas Bagian adalah tundaan rata-rata lalu lintas per kendaraan yang masuk ke bagian jalinan. Tundaan lalu lintas diten-tukan dari hubungan antara tundaan lalu lintas dan derajat kejenuhan, yang di tentukan dengan persamaan berikut (MKJI,1997):

$$
\mathrm{DT}=2+(2,68982 \times \mathrm{DS})-(1-\mathrm{DS}) \times 2
$$

$$
\text { untuk DS } \leq 0,6 \text {. }
$$

$$
\begin{aligned}
& \mathrm{DT}=\frac{1}{(0,59186-0,52525 \times \mathrm{DS})}-(1-\mathrm{DS}) \times 2 \text {; } \\
& \text { untuk DS > 0,6. }
\end{aligned}
$$

\section{Tundaan Lalu Lintas Bundaran (DTR)}

Tundaan lalu lintas bundaran adalah tundaan rata-rata per kendaraan yang masuk kedalam bundaran. Dihitung sebagai berikut (MKJI,1997):

$\mathrm{DTR}=\Sigma(\mathrm{Qi} \times \mathrm{DTi}) /$ Qmasuk

Dimana Qi adalah arus total pada bagian jalinan I, DTi adalah tundaan lalu lintas rata-rata pada bagian jalinan i dan Qmasuk yaitu jumlah arus yang masuk bundaran (smp).

\section{Tundaan Bundaran (DR)}

Tundaan bundaran adalah tundaan lalu lintas rata-rata per kendaraan masuk bundaran dan dihitung sebagai berikut (MKJI,1997):

$\mathrm{DR}=\mathrm{DTR}+4$

Dimana DR adalah tundaan bundaran, dan DTR adalah tundaan lalu lintas bundaran.

\section{Peluang Antrian Bagian Jalinan}

Peluang antrian dihitung dari hubungan antara peluang antrian dengan derajat kejenuhan, yang dihitung menggunakan persamaan berikut (MKJI,1997):

$$
\mathrm{QP} \% \min =\begin{array}{ccc}
(9,41 & \mathrm{x} & \mathrm{DS}) \\
\left.\mathrm{DS}^{4,619}\right) \ldots \ldots \ldots \ldots \ldots \ldots \ldots \ldots \ldots \ldots \ldots \ldots \ldots \ldots \ldots \ldots \ldots
\end{array}
$$

$$
\mathrm{QP} \% \text { maks }=(26,65 \times \mathrm{DS})-\left(55,55 \times \mathrm{DS}^{2}\right)+
$$$$
\left(108,57 \times \mathrm{DS}^{3}\right) \ldots \ldots \ldots \ldots \ldots \ldots(8)
$$

\section{Tingkat Pelayanan}

Tingkat pelayanan adalah perbedaan kondisi operasional yang terjadi pada suatu jalan sewaktu jalan tersebut melayani berbagai macam volume lalu lintas. Untuk mendapat-kan kinerja suatu bundaran perlu dilakukan perhitungan derajat kejenuhan dan tundaan lalu lintas bundaran. Tingkat pelayanan dikategorikan dari yang terbaik (tingkat pelayanan A) sampai yang terburuk (tingkat pelayanan F).(Tamin, 2000). 


\section{METODE PENELITIAN}

\section{Lokasi Penelitian}

Penelitian ini berlokasi di Kota Kuala Kurun Kabupaten Gunung Mas, Kalimantan Tengah tepatnya di Bundaran Duhung. Bundaran ini melayani arus lalu lintas dari berbagai arah, yaitu Jalan Ahmad Yani, Jalan Jalan Tjilik Riwut dan Jalan Kopri.

\section{Pengumpulan Data}

Data yang digunakan untuk dianalisa didapat dengan cara pengumpulan data primer dan data sekunder sesuai dengan kebutuhan penelitian. Metode pengumpulan data yang dilakukan adalah sebagai berikut:

\section{Data Primer}

Data Primer merupakan data yang didapatkan secara langsung dilapangan atau pada lokasi penelitian.

Pengumpulan data primer untuk analisa data yaitu sebagai berikut:

a. Data geometrik bundaran yaitu pengumpulan data yang dilakukan dengan mengadakan observasi terhadap kondisi geometrik bundaran yang meliputi diameter bundaran, lebar pendekat $\left(\mathrm{W}_{1}\right)$ dan $\left(\mathrm{W}_{2}\right)$, lebar jalinan $(\mathrm{WW})$, panjang jalinan (Lw).

b. Data volume lalu lintas yaitu pengumpulan yang dilakukan dengan cara mengelompokkan jenis kendaraan yang lewat.

c. Kondisi lingkungan yaitu dengan melihat langsung di lokasi penelitian untuk menentukan tipe lingkungan jalan berupa kawasan permukiman, komersial, atau akses terbatas dan kelas hambatan samping.

\section{Data Sekunder}

Data sekunder merupakan data yang diperoleh dari instansi terkait atau berwenang dalam penyediaan data yang berhubungan dengan masalah yang menjadi objek penelitian. Data sekunder tersebut meliputi jumlah penduduk di kota Palangka Raya, jumlah kepemlikan kendaraan di Kota Palangkaraya, peta lokasi dan dokumentasi.

\section{Waktu Penelitian}

Penelitian ini dilaksanakan selama 1 (satu) minggu, pada hari pertama penelitian dilakukan selama 12 (dua belas) jam untuk menentukan jam sibuk penelitian pada hari berikutnya yaitu jam sibuk selama dua jam pada pagi hari, siang hari, dan sore hari.

\section{Bagan Alir Penelitian}

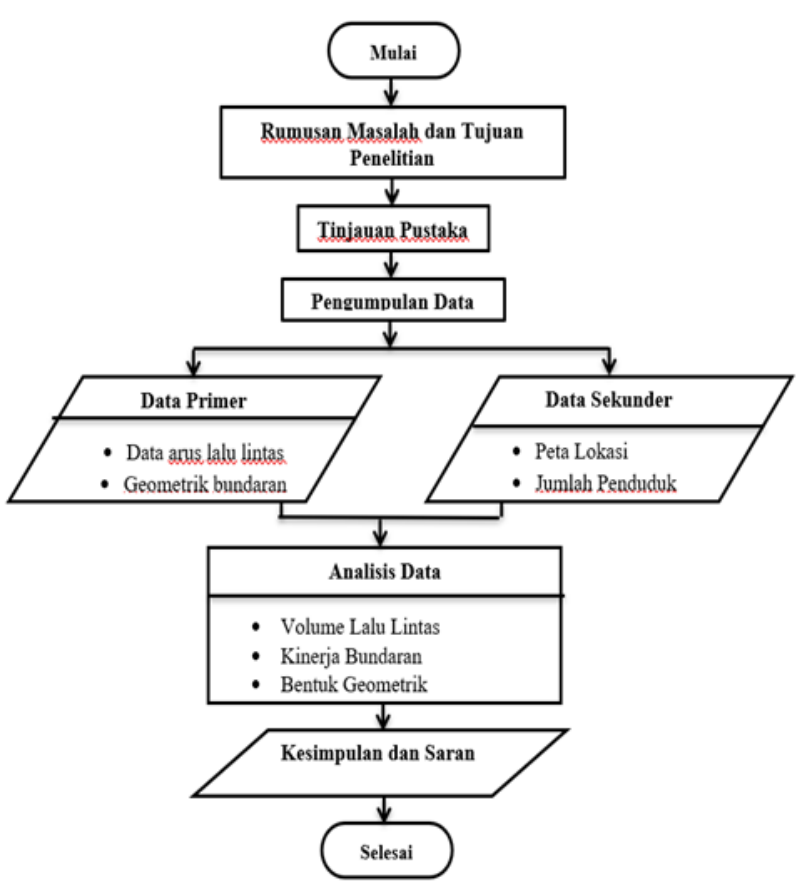

Gambar 1 Bagan Alir Penelitian

\section{HASIL ANALISIS DAN PEMBAHASAN}

\section{Geometrik Bagian Jalinan}

Data mengenai ukuran (panjang dan lebar) jalinan pada lokasi Bundaran Duhung yang diukur dalam $\mathrm{m}$ (meter).

Tabel 3. Ukuran Geometrik

\begin{tabular}{cccccc}
\hline $\begin{array}{c}\text { Bagian } \\
\text { Jalinan }\end{array}$ & $\begin{array}{c}\text { W1 } \\
(\mathrm{m})\end{array}$ & $\begin{array}{c}\mathrm{W} 2 \\
(\mathrm{~m})\end{array}$ & $\begin{array}{c}\text { We } \\
(\mathrm{M})\end{array}$ & $\begin{array}{c}\text { Ww } \\
(\mathrm{m})\end{array}$ & $\begin{array}{c}\text { Lw } \\
(\mathrm{m})\end{array}$ \\
\hline $\mathrm{AB}$ & 9,30 & 20,10 & 14,70 & 12,60 & 53,60 \\
$\mathrm{BC}$ & 6,44 & 14,30 & 10,37 & 9,70 & 45,00 \\
$\mathrm{CD}$ & 4,70 & 9,60 & 7,15 & 10,55 & 49,00 \\
$\mathrm{DA}$ & 7,20 & 20,00 & 13,60 & 13,60 & 57,19 \\
\hline
\end{tabular}

Sumber Analisis Data (2020)

\section{Volume Lalu Lintas}

Dari hasil survei selama 7 hari, diperoleh volume kendaraan terbesar pada hari Rabu Pukul 06.00-07.00 WIB, yaitu sebesar $1.311 \mathrm{smp} / \mathrm{jam}$, dimana arus bagian jalinan $\mathrm{AB}$ yaitu $815 \mathrm{smp} / \mathrm{jam}$, jalinan BC sebesar $739 \mathrm{smp} / \mathrm{jam}$, jalinan CD adalah 794 smp/jam, serta jalinan DA yaitu $700 \mathrm{smp} / \mathrm{jam}$. 


\section{Kapasitas}

Berdasarkan hasil analisis perhitungan menggunanakan metode Manual Kapasitas Jalan Indonesia 1997, diperoleh nilai kapasitas seperti pada Tabel 4 di bawah ini.

Tabel 4. Kapasitas Jalinan Bundaran

\begin{tabular}{|c|c|c|c|c|}
\hline \multirow{2}{*}{$\begin{array}{l}\text { Bagian } \\
\text { jalinan }\end{array}$} & \multirow{2}{*}{$\begin{array}{c}\text { Kapasitas } \\
\text { dasar } \\
(\mathrm{Co}) \\
\text { smp/jam } \\
\end{array}$} & \multicolumn{2}{|c|}{ Faktor Penyesuaian } & \multirow{2}{*}{$\begin{array}{r}\text { Kapasitas } \\
\text { (smp/jam) }\end{array}$} \\
\hline & & $\left(\mathrm{F}_{\mathrm{CS}}\right)$ & $\left(\mathrm{F}_{\mathrm{RSU}}\right)$ & \\
\hline $\mathrm{AB}$ & 6.803 & 0,82 & 0,940 & 5.244 \\
\hline $\mathrm{BC}$ & 5.006 & 0,82 & 0,940 & 3.859 \\
\hline CD & 3.759 & 0,82 & 0,940 & 2.897 \\
\hline DA & 6.730 & 0,82 & 0,940 & 5.187 \\
\hline
\end{tabular}

Sumber Analisis Data (2020)

\section{Perilaku Lalu Lintas}

Hasil analisis perhitungan menggunanakan metode Manual Kapasitas Jalan Indonesia 1997, diperoleh nilai derajat kejenuhan dan tundaan lalu lintas jalinan tertinggi pada jali-nan CD sebesar 0,274 dan 2,07 det/smp dan Bundaran Burung memiliki nilai tundaan lalu lintas bundaran rata-rata sebesar 6,07 det/smp dan peluang antrian sebesar 2,6\%-11,2\%. Hasil analisis perilaku tiap jalinan pada Tabel 1 yang terdapat pada lampiran.

\section{Geometrik Bundaran}

Bentuk geometrik bundaran dihitung menggunakan rumus kemiringan lereng berikut ini (2-9), yaitu :

$$
\begin{aligned}
S & =(45,3814-45,9304) / 25 \times 100 \% \\
& =2,196
\end{aligned}
$$

\begin{tabular}{|c|c|c|c|c|c|c|c|}
\hline \multicolumn{8}{|c|}{ PERHITUNGAN \% KELANDAIAN JALAN } \\
\hline \multirow{2}{*}{ No } & \multirow{2}{*}{ Nama Jalan } & \multirow{2}{*}{ STA } & Elevasi & Elevasi & Jarak & Kelandaian & Kelandaian \\
\hline & & & Muka & Blakang & (m) & $(\%)$ & $(\%)$ \\
\hline \multirow{3}{*}{1} & \multirow{3}{*}{ A.Yani } & Sta $00+000-00+025$ & 45,3814 & 45,9304 & 25 & 2,196 & \multirow{3}{*}{2,825} \\
\hline & & Sta $00+025-00+050$ & 45,9304 & 47,0344 & 25 & 4,416 & \\
\hline & & Sta $00+050-00+075$ & 47,0344 & 47,5004 & 25 & 1,864 & \\
\hline \multirow{3}{*}{2} & \multirow{3}{*}{$\begin{array}{c}\text { Cilik Riwut } \\
\text { B }\end{array}$} & Sta $00+000-00+025$ & 49,3374 & 51,4824 & 25 & 8,58 & \multirow{3}{*}{1,424} \\
\hline & & Sta $00+025-00+050$ & 51,4824 & 49,3754 & 25 & $-8,428$ & \\
\hline & & Sta $00+050-00+075$ & 49,3754 & 50,4054 & 25 & 4,12 & \\
\hline \multirow{3}{*}{3} & \multirow{3}{*}{$\begin{array}{c}\text { Cilik Riwut } \\
\text { D }\end{array}$} & Sta $00+000-00+025$ & 44,7886 & 43,3066 & 25 & $-5,928$ & \multirow{3}{*}{$-5,800$} \\
\hline & & Sta $00+025-00+050$ & 43,3066 & 41,1576 & 25 & $-8,596$ & \\
\hline & & Sta $00+050-00+075$ & 41,1576 & 40,4386 & 25 & $-2,876$ & \\
\hline \multirow{3}{*}{4} & \multirow{3}{*}{ Kopri } & Sta $00+000-00+025$ & 47,2502 & 45,8292 & 25 & $-5,684$ & \multirow{3}{*}{$-3,425$} \\
\hline & & Sta $00+025-00+050$ & 45,8292 & 44,4312 & 25 & $-5,592$ & \\
\hline & & Sta $00+050-00+075$ & 44,4312 & 44,6812 & 25 & 1 & \\
\hline
\end{tabular}

Tabel 5. Hasil Analisis Geometrik Bundaran Duhung pada Tahun 2020

Sumber: Analisis Data (2020)

\section{PENUTUP}

\section{Kesimpulan}

Berdasarkan hasil analisis dan perhitungan, maka dapat disimpulkan sebagai berikut: :

1. Arus lalu lintas pada Bundaran Duhung Kota Kuala Kurun pada masing-masing bagian jalinan, yaitu AB (Jalan Ahmad Yani-Jalan Tjilik Riwut) sebesar $815 \mathrm{smp} / \mathrm{jam}$, jalinan BC (Jalan Tjilik Riwut-Jalan Kopri) sebesar 739 smp/jam, jalinan CD (Jalan Kopri-Jalan Tjilik Riwut) sebesar 794 smp/jam dan jalinan DA (Jalan Tjilik Riwut-Jalan Ahmad Yani) sebesar $700 \mathrm{smp} / \mathrm{jam}$. Arus bagian jalinan yang tertinggi yaitu pada jalinan AB (Jalan Ahmad Yani-Jalan 
Tjilik Riwut) dan arus bagian jalinan yang terendah pada jalinan DA (Jalan Tjilik RiwutJalan Ahmad Yani).

2. Kapasitas pada Bundaran Duhung Kota Kuala Kurun di masing-masing bagian jali-nan, yaitu AB (Jalan Ahmad Yani-Jalan Tjilik Riwut) sebesar $6.803 \mathrm{smp} / \mathrm{jam}, \mathrm{BC}$ (Jalan Tjilik RiwutJalan Kopri) sebesar 5.006 smp/jam, CD (Jalan Kopri-Jalan Tjilik Riwut) sebesar 3.759 smp/jam, dan DA (Jalan Tjilik Riwut-Jalan Ahmad Yani) sebesar $6.730 \mathrm{smp} / \mathrm{jam}$. Kapasitas bagian jalinan yang terbesar terletak pada bagian jalinan AB (Jalan Ahmad Yani-Jalan Tjilik Riwut) dan yang terkecil terletak pada ba-gian jalinan CD (Jalan Kopri-Jalan Tjilik Riwut). Nilai derajat kejenuhan tertinggi dari jalinan CD (Jalan Kopri-Jalan Tjilik Riwut) adalah 0,274, tundaan lalu lintas bundaran rata-rata (DTR) yaitu $2,07 \mathrm{det} / \mathrm{smp}$, dan tundaan bundaran ratarata (DR) yaitu $6,07 \mathrm{det} / \mathrm{smp}$, serta peluang antrian sebesar 2,6\%-11,2\%. Sehingga dapat disimpulkan bahwa Bundaran Burung memiliki karakteristik tingkat pelayanan pada kondisi sekarang adalah kelas A.

3. Geometrik Bundaran Duhung memiliki nilai kelandaian yang terbesar yaitu $-5,800 \%$, pada lengan D (Jalan Tjilik Riwut), dan pada lengan A (Jalan Ahmad Yani), yaitu 2,824\%, dan pada lengan B (Jalan Tjilik Riwut) adalah 1,424\%, dan pada lengan C (Jalan Kopri) yaitu $-3,425 \%$. Dari hasil penelitian geometrik bundaran pada lengan D (Jalan Tjilik Riwut) tidak memenuhi syarat batas maksimum yaitu $4 \%$, sehingga tidak dapat memenuhi kenyamanan pengguna jalan.

\section{Saran}

Berdasarkan kesimpulan yang diperoleh dari hasil penelitian, maka dapat diberikan beberapa saran sebagai berikut :

1. Perlu adanya penambahan pemasangan rambu lalu lintas (rambu hati-hati).

2. Kedisiplinan pengemudi dalam mentaati peraturan lalu lintas perlu lebih ditingkat-kan karena banyak pelanggaran yang dil-akukan seperti putar balik yang tidak pada tempat seharus nya.

\section{DAFTAR PUSTAKA}

Alamsyah, A, (2005), Rekayasa Lalu Lintas, Universitas. Muhammadiyah Malang. Malang.
Direktorat Jenderal Bina Marga, (1997), Manual Kapasitas Jalan Indonesia (MKJI), Jakarta

Hobbs, F.D., (1995), Perencanaan dan Teknik Lalu Lintas. Penerbit Gadjah Mada, Yogyakarta.

Morlok, E.K., (1991), Pengantar Teknik dan Perencanaan Transportasi. Erlangga. Jakarta.

Mulyawan, S. H, (2010), Analisis Kemampuan Bundaran Dalam Melayani Arus Lalu Lintas. (Studi Kasus Bundaran Dharma Wanita Kota Buntok). Skripsi Fakultas Teknik Universitas Palangka Raya, Palangka Raya.

Pd.T-20-2004-B. Perencanaan Bundaran untuk Persimpangan Sebidang

Sudjana., (1991), Metode Statistika, Tarsito, Bandung. 